\title{
Nilai APGAR, Trauma Lahir Mekanik dan Mortalitas Neonatal Dini pada Bayi Lahir dengan Presentasi Bokong Di RSUPN Gipto Mangunkusumo
}

\author{
Wynda Felisia, Asril Aminullah, Sudigdo Sastroasmoro \\ Departemen Ilmu Kesehatan Anak Fakultas Kedokteran Universitas Indonesia, RS. Dr. cipto Mangunkusumo, \\ Jakarta
}

\begin{abstract}
Latar belakang. Presentasi bokong merupakan bentuk malpresentasi tersering yang ditemukan pada kehamilan cukup bulan, sekitar 3\%-4\% kelahiran. Fasilitas dan pelayanan kebidanan telah banyak mencatat kemajuan, namun mortalitas dan morbiditas bayi presentasi bokong 2-3 kali lebih tinggi dibanding presentasi kepala.

Tujuan. Mengetahui gambaran nilai APGAR, trauma lahir mekanik dan mortalitas neonatal dini pada bayi presentasi bokong.

Metode. Penelitian retrospektif pada bayi yang lahir dengan presentasi bokong di RSUPN Cipto Mangunkusumo pada 1 Januari 2004 sampai dengan 31 Desember 2005. Kriteria inklusi adalah bayi presentasi bokong yang lahir hidup, usia gestasi $>28$ minggu. Kriteria eksklusi apabila dijumpai lahir mati dan malformasi kongenital berat.

Hasil. Terdapat 386 bayi lahir dengan presentasi bokong yang memenuhi kriteria inklusi penelitian. Mortalitas neonatal dini lebih sering terjadi pada persalinan pervaginam dibanding bedah kaisar (12,2\% vs 2,8\%). Nilai Apgar menit ke- $5<7$ lebih sering pada persalinan pervaginam dibanding bedah kaisar (12,9\% vs 4,0\%). Trauma lahir mekanik lebih sering pada persalinan pervaginam dibanding bedah kaisar $(14 / 139,10,1 \%$ vs $15 / 247,6,1 \%)$ Kesimpulan. Mortalitas neonatal dini, nilai Apgar rendah dan trauma lahir mekanik pada bayi presentasi bokong lebih sering terjadi pada persalinan pervaginam (Sari Pediatri 2008;9(6):412-6).
\end{abstract}

Kata kunci: presentasi bokong, nilai Apgar, trauma lahir mekanik, mortalitas neonatal dini.

\footnotetext{
Alamat korespondensi

Prof. Dr. Asril Aminullah, Sp.A(K), Guru Besar Departemen Ilmu Kesehatan Anak, Fakultas Kedokteran Universitas Indonesia, Divisi Perinatologi, Jl. Salemba Raya No.6 Jakarta 10430 Telp. 021-316-0622, Fax.: 021-316-0622

Dr. Wynda Felisia, Peserta Program Studi Dokter Spesialis Ilmu Kesehatan Anak, Departemen Ilmu Kesehatan Anak Fakultas Kedokteran Universitas Indonesia, Jl. Salemba Raya No.6 Jakarta 10430 Telp. 021316-0622, E-mail: Wyndafe5@yahoo.com
}

$\mathrm{P}$ resentasi bokong merupakan bentuk tersering malpresentasi yang ditemukan pada kehamil an cukup bulan, yaitu 3\%-4\% kelahiran. ${ }^{1-4}$ Walaupun fasilitas dan pelayanan kebidanan telah banyak mengalami kemajuan, namun mortalitas dan morbiditas kelahiran bayi presentasi bokong 2-3 kali lebih tinggi dibanding presentasi kepala. Hal ini berkaitan dengan adanya malformasi janin, prematuritas dan kematian janin intrauterin. ${ }^{1,2}$ 
Tata laksana terbaik persalinan presentasi bokong atau persalinan sungsang saat ini masih menjadi perdebatan. Di Indonesia persalinan pervaginam masih menjadi pilihan pertama untuk tata laksana persalinan sungsang. Untuk mengurangi morbiditas dan mortalitas, beberapa negara memilih bedah kaisar dalam tata laksana bayi lahir sungsang. Namun demikian persalinan bedah kaisar tidak dapat menjamin secara pasti bayi akan bebas dari trauma lahir.

Hannah $\mathrm{dkk}^{3}$ dalam penelitian prospektif multisenter, the term breech trial (TBT), melaporkan mortalitas dan morbiditas perinatal 3 kali lebih tinggi pada bayi sungsang yang lahir pervaginam dibandingkan dengan persalinan bedah kaisar. Demikian pula di beberapa penelitian di Skandinavia memperlihatkan kejadian gangguan neurologis pada bayi lahir pervaginam meningkat dibandingkan bedah kaisar elektif atau bayi presentasi kepala. Oleh karena itu pada bayi presentasi bokong cukup bulan lebih banyak dipiilih bedah kaisar elektif. ${ }^{5,6}$

Uji retrospektif yang dilakukan selama 7 tahun oleh Kayem dkk, ${ }^{1}$ menyimpulkan bahwa pada bayi presentasi bokong tidak terdapat perbedaan morbiditas dan mortalitas yang bermakna antara kelahiran bayi pervaginam dibandingkan dengan bedah kaisar. Demikian pula Uotila $\mathrm{dkk}^{7-9} \mathrm{dan}$ beberapa peneliti lain mendapatkan hasil perinatal yang baik pada persalinan sungsang pervaginam.

Tujuan penelitian ini adalah untuk mengetahui sebaran nilai Apgar, insidens trauma lahir mekanik dan mortalitas neonatal dini pada bayi presentasi bokong yang lahir pervaginam dan bedah kaisar di RSUPN Cipto Mangunkusumo.

\section{Metode}

Penelitian retrospektif dengan data dari rekam medis bayi yang lahir presentasi bokong di Divisi Perinatologi Departemen Ilmu Kesehatan Anak FKUI/RSCM selama kurun waktu 1 Januari 2004-31 Desember 2005. Kriteria inklusi ialah bayi dengan presentasi bokong, usia kehamilan $\geq 28$ minggu, bayi tunggal maupun kembar. Bayi tidak diikutkan dalam penelittian bila lahir pada usia kehamilan $<28$ minggu, lahir mati, atau terdapat kelainan kongenital mayor.

Perhitungan besar sampel dilakukan dengan menggunakan tingkat kesalahan tipe I 5\% dan tingkat ketepatan absolut yang dikehendaki 5\%, dan didapatkan subjek penelitian 138 pasien. Dinilai sebaran angka Apgar menit ke-1 dan ke-5, trauma lahir mekanik berat ataupun ringan, dan mortalitas neonatal dini (kematian bayi dalam 7 hari pertama).

\section{Hasil}

Selama kurun waktu 2 tahun dari 1 Januari 2004 hingga 31 Desember 2005 terdapat 6561 kelahiran dengan 419 pasien lahir dengan presentasi bokong $(6,4 \%)$, dan yang memenuhi kriteria inklusi 386 pasien.

Karakteristik subjek penelitian tertera dalam Tabel 1 menunjukkan bahwa sebagian besar subjek penelitian adalah bayi dengan usia gestasi $>37$ minggu, $(80,1 \%)$ dan angka mortalitas neonatal dini 6,2\% (24 dari 386 bayi) dengan karakteristik seperti tertera pada Tabel 2. Angka mortalitas tidak mencakup mortalitas akibat lahir mati atau malformasi kongenital berat.

Pada Tabel 2 nilai Apgar menit ke-1 kurang dari 7 tersering ditemukan pada pasien dengan usia gestasi 28-32 minggu, berat lahir $<2500$ g, primipara, dan lahir pervaginam. Bayi dengan nilai Apgar menit ke-5 $<7$ paling sering terjadi pada pasien dengan usia gestasi 28-32 minggu (48\%, 13 dari 27 bayi), berat lahir $<2500 \mathrm{~g}(17,2 \%, 20$ dari 116 bayi), primipara $(8,1 \%, 15$ dari 185 bayi), dan persalinan pervaginam dibanding bedah kaisar (12,9\% dibanding 4\%). Trauma lahir mekanik berat hanya ditemukan satu kasus, yaitu palsi Erb's yang terjadi pada usia gestasi $>37$ minggu, pada kelompok berat lahir antara 2500-3800 g dan lahir pervaginam. Trauma lahir mekanik ringan paling sering terjadi pada usia gestasi $28-32$ minggu (11\%, 3 dari 27 bayi), berat lahir <2500g ( 8,6\%, 10 dari 116 bayi), primipara (11,4\%, 21 dari 185 bayi), dan lahir pervaginam (yaitu $10,1 \%$ ) sedangkan pada bedah kaisar ditemukan 6,1\% kasus.

Trauma lahir mekanik ringan ditemukan pada 29 kasus dan paling sering ditemukan adalah trauma genitalia 11 kasus, trauma di daerah kepala 8 kasus, dan trauma di tungkai bawah 7 kasus. Terdapat 1 kasus tortikolis dan 2 kasus dengan jejas di daerah abdomen. Trauma kepala meliputi hematoma, jejas kemerahan, dan bentuk kepala asimetri. Trauma di daerah tungkai terlihat adanya edema, hematoma, dan laserasi di daerah gluteus (Tabel 3). 
Tabel 1. Karakteristik subjek penelitian

\begin{tabular}{|c|c|c|c|c|c|c|}
\hline \multirow{3}{*}{ Karakteristik } & \multicolumn{4}{|c|}{ Cara kelahiran } & \multicolumn{2}{|c|}{ Total } \\
\hline & \multicolumn{2}{|c|}{ Pervaginam } & \multicolumn{2}{|c|}{ Bedah kaisar } & \multirow{2}{*}{ n (386) } & \multirow{2}{*}{$\%$} \\
\hline & n (139) & $\%$ & n (247) & $\%$ & & \\
\hline \multicolumn{7}{|l|}{ Usia gestasi (minggu) } \\
\hline $28-32$ & 18 & 67 & 9 & 33 & 27 & 7.0 \\
\hline $33-36$ & 24 & 48 & 26 & 52 & 50 & 12.9 \\
\hline$>37$ & 97 & 31,4 & 212 & 68,6 & 309 & 80.1 \\
\hline \multicolumn{7}{|l|}{ Paritas } \\
\hline 0 & 56 & 30,3 & 129 & 69,7 & 185 & 47.9 \\
\hline $1-3$ & 67 & 40,4 & 99 & 59,6 & 166 & 43.0 \\
\hline$\geq 4$ & 16 & 46 & 19 & 54 & 35 & 9.1 \\
\hline \multicolumn{7}{|l|}{ Jenis presentasi } \\
\hline Bokong & 113 & 35,3 & 207 & 64,7 & 320 & 82.9 \\
\hline Bokong-kaki & 7 & 39 & 11 & 61 & 18 & 4.7 \\
\hline Kaki ${ }^{\circ}$ & 19 & 40 & 29 & 60 & 48 & 12.4 \\
\hline \multicolumn{7}{|l|}{ Berat lahir (gram) } \\
\hline$<2500$ & 56 & 48,3 & 60 & 51,7 & 116 & 30,1 \\
\hline $2500-3800$ & 82 & 32,2 & 173 & 67,8 & 255 & 66,1 \\
\hline$>3800$ & 1 & 7 & 14 & 93 & 15 & 3,8 \\
\hline Ketuban pecah dini & 45 & 30,2 & 104 & 69,8 & 149 & 38,6 \\
\hline Morbiditas kehamilan & 17 & 25 & 51 & 75 & 68 & 17,6 \\
\hline
\end{tabular}

Tabel 2. Sebaran mortalitas neonatal dini, nilai Apgar dan trauma mekanik pada bayi presentasi bokong $(\mathrm{n}=386)$

\begin{tabular}{|c|c|c|c|c|c|c|c|c|c|c|}
\hline \multirow[t]{2}{*}{ Karakteristik } & \multicolumn{2}{|c|}{$\begin{array}{c}\text { Mortalitas } \\
\text { neonatal dini }\end{array}$} & \multicolumn{2}{|c|}{$\begin{array}{l}\text { Nilai APGAR } \\
\text { menit ke-1 }(<7)\end{array}$} & \multicolumn{2}{|c|}{$\begin{array}{l}\text { Nilai APGAR } \\
\text { menit ke-5 }(<7)\end{array}$} & \multicolumn{2}{|c|}{$\begin{array}{c}\text { Trauma } \\
\text { mekanik berat }\end{array}$} & \multicolumn{2}{|c|}{$\begin{array}{c}\text { Trauma mekanik } \\
\text { ringan }\end{array}$} \\
\hline & $\begin{array}{c}\mathrm{Ya} \\
(\mathrm{n}=24)\end{array}$ & $\%$ & $(\mathrm{n}=91)$ & $\%$ & $(\mathrm{n}=28)$ & $\%$ & $(\mathrm{n}=1)$ & $\%$ & $(\mathrm{n}=29)$ & $\%$ \\
\hline \multicolumn{11}{|c|}{ Usia gestasi (minggu) } \\
\hline $28-32$ & 13 & 48 & 21 & 78 & 13 & 48 & 0 & 0 & 3 & 11 \\
\hline $32-36$ & 7 & 14 & 17 & 34 & 4 & 8 & 0 & 0 & 5 & 10 \\
\hline$>37$ & 4 & 1,3 & 53 & 17,2 & 11 & 3,6 & 1 & 0,3 & 21 & 6,8 \\
\hline \multicolumn{11}{|l|}{ Berat lahir (g) } \\
\hline$<2500$ & 21 & 18 & 48 & 41,4 & 20 & 17,2 & 0 & 0,0 & 10 & 8,6 \\
\hline $2500-3800$ & 3 & 1,2 & 41 & 16,1 & 8 & 3,1 & 1 & 0,4 & 19 & 7,5 \\
\hline$>3800$ & 0 & 0 & 2 & 13 & 0 & 0 & 0 & 0 & 0 & 0 \\
\hline \multicolumn{11}{|l|}{ Paritas } \\
\hline Primipara & 8 & 4,3 & 44 & 23,8 & 15 & 8,1 & 0 & 0,0 & 21 & 11,4 \\
\hline $1-3$ & 13 & 7,8 & 40 & 24,1 & 12 & 7,2 & 1 & 0,6 & 7 & 4,2 \\
\hline$>3$ & 3 & 9 & 7 & 20 & 1 & 3 & 0 & 0 & 1 & 2 \\
\hline \multicolumn{11}{|l|}{ Cara kelahiran } \\
\hline Pervaginam & 17 & 12,2 & 48 & 35,5 & 18 & 12,9 & 1 & 0,7 & 14 & 10,1 \\
\hline Bedah kaisar & 7 & 2,8 & 43 & 17,4 & 10 & 4,0 & 0 & 0,0 & 15 & 6,1 \\
\hline
\end{tabular}

\section{Diskusi}

Dalam kurun waktu 24 bulan di Divisi Neonatologi RSCM/FKUI terdapat 419 pasien presentasi bokong dari keseluruhan 6561 kelahiran bayi (6,4\%). Tidak berbeda dengan penelitian Bakry dkk pada tahun 1972 dan 1973 di RSCM, yaitu insidens presentasi bokong masing-masing 6,9 dan 5,4\%, sedangkan berdasarkan kepustakaan insidens presentasi bokong berkisar 34\%. ${ }^{4,10} \mathrm{Hal}$ ini bisa terjadi karena RSCM merupakan rumah sakit rujukan.

Angka mortalitas neonatal dini 6,2\%, lebih rendah 
Wynda Felisia dkk: Nilai APGAR, Trauma Lahir Mekanik dan Mortalitas Neonatal Dini pada Bayi Lahir dengan Presentasi Bokong

Tabel 3. Jenis trauma lahir mekanik

\begin{tabular}{lcc}
\hline Karakteristik & \multicolumn{2}{c}{ Jumlah $(\mathrm{n}=386)$} \\
\cline { 2 - 3 } & $\mathrm{n}$ & $\%$ \\
\hline $\begin{array}{l}\text { Trauma lahir berat }(\mathrm{n}=1) \\
\quad \text { Palsi Erb's }\end{array}$ & 1 & 0,3 \\
Trauma lahir ringan $(\mathrm{n}=29)$ & & \\
$\quad$ Trauma di daerah kepala & 8 & 2,1 \\
$\quad$ Tortikolis & 1 & 0,3 \\
$\quad$ Trauma di daerah abdomen & 2 & 0,5 \\
$\quad$ Trauma genitalia & 11 & 2,8 \\
$\quad$ Trauma di daerah tungkai & 7 & 1,8 \\
\hline
\end{tabular}

dibanding penelitian Bakry dkk pada tahun 1972 dan 1973 yang masing-masing mencapai $13,2 \%$ dan $10,6 \%$. Temuan ini mencerminkan semakin membaiknya pelayanan kebidanan dan perinatologi, dan mungkin juga disebabkan tindakan yang lebih agresif untuk menolong persalinan sungsang mengingat angka bedah kaisar yang cukup tinggi, (64\%).

Mortalitas neonatal dini pada bayi sungsang pervaginam 4 kali lebih tinggi dibanding bedah kaisar (12,2\% vs 2,8\%), sesuai dengan penelitian Hannah dkk yang mendapatkan mortalitas neonatal 3 kali lebih tinggi pada persalinan sungsang pervaginam. ${ }^{3}$ Di RSCM persalinan pervaginam masih menjadi pilihan utama dalam menolong persalinan sungsang. Tingginya angka kematian bayi lahir sungsang pervaginam tidak hanya dipengaruhi oleh cara kelahiran, namun banyak faktor yang berperan seperti berat lahir, morbiditas ibu dan janin, ketuban pecah dini dan lain-lain.

Nilai Apgar secara luas telah digunakan untuk menilai derajat asfiksia intrapartum. Nilai Apgar menit ke- $1<7$ terjadi pada $23,6 \%$ kasus, sedangkan pada penelitian Harahap ${ }^{11} 42,3 \%$. Nilai Apgar menit ke-5 $<7$ pada penelitian ini terdapat pada 7,3\% kasus, sedangkan pada penelitian Harahap 19,2\% kasus. Angka kejadian nilai Apgar $<7$ pada penelitian ini lebih rendah dibanding penelitian Harahap.

Nilai Apgar $<7$ lebih sering terjadi pada persalinan sungsang pervaginam dibanding bedah kaisar, sesuai dengan penelitian sebelumnya yang dilakukan oleh Herbst dkk maupun Belgafe dkk. ${ }^{5,6}$ Berdasarkan usia gestasi dan berat lahir maka nilai Apgar $<7$ lebih sering terjadi pada kelompok bayi prematur dan berat lahir rendah, tanpa mempertimbangkan cara kelahiran. Prematuritas dan berat lahir rendah berperan penting dalam terjadinya asfiksia. ${ }^{12}$
Berdasarkan paritas ibu, nilai Apgar menit ke-5 $<7$ lebih sering terjadi pada primipara dibanding nonprimi, sesuai dengan penelitian Lieberman ${ }^{13}$ yang mendapatkan asfiksia lebih sering terjadi pada primipara. Heija $\mathrm{dkk}^{9}$ mendapatkan 6 kasus asfiksia dari 67 bayi yang lahir dari ibu primipara yang lahir pervaginam dibanding 0 kasus yang lahir bedah kaisar.

Sebagian besar trauma lahir mekanik yang terjadi adalah trauma lahir ringan 7,8\% (30 dari 386 bayi), jauh lebih rendah dibanding penelitian Harahap yaitu 38\% (30 dari 78 bayi). Trauma lahir berat hanya ditemukan pada 1 kasus $(0,3 \%, 1$ dari 386 bayi), yaitu 1 kasus palsi Erb's yang telah dikonfirmasi oleh ahli saraf anak. Harahap juga menemukan 1 kasus palsy Erb's dari 78 bayi yang lahir di RSCM pada tahun 1986. Pada penelitian Bakry pada tahun 1972 dan 1973 didapatkan angka trauma lahir masing-masing $6,4 \%$ dan 4,5\%, namun lebih sering ditemukan trauma yang berat antara lain fraktur klavikula, fraktur humerus, paresis Erbs, kelumpuhan saraf frenikus, kelumpuhan saraf otak ke VII, perdarahan subaponeurotik dan sefalhematom. ${ }^{10}$ Trauma lahir mekanik ringan ini meliputi trauma genitalia 11 kasus, trauma di daerah kepala 8 kasus, dan trauma di daerah tungkai bawah 7 kasus. Terdapat 1 kasus tortikolis dan 2 kasus dengan jejas di daerah abdomen. Trauma genitalia bervariasi dari edema labia atau skrotum hingga hematoma. Trauma di daerah kepala meliputi adanya hematoma, jejas kemerahan, dan bentuk kepala asimetri. Trauma di daerah tungkai meliputi edema, hematoma, dan laserasi di daerah gluteus. Trauma lahir ringan umumnya dapat sembuh sempurna dan tidak mengancam nyawa namun dapat menjadi sumber kecemasan orangtua. Dokter anak berperan untuk memberi penjelasan dan pengertian yang tepat pada orangtua mengenai trauma yang diderita.

\section{Kesimpulan dan saran}

Mortalitas neonatal dini dan nilai Apgar rendah pada bayi presentasi bokong lebih sering terjadi pada bayi prematur, berat lahir rendah, dan lahir pervaginam. Trauma lahir mekanik pada bayi presentasi bokong lebih sering terjadi pada primipara, usia gestasi $>37$ minggu, dan lahir pervaginam. Temuan ini dapat menjadi pertimbangan melakukan persalinan bedah kaisar pada presentasi bokong. 
Wynda Felisia dkk: Nilai APGAR, Trauma Lahir Mekanik dan Mortalitas Neonatal Dini pada Bayi Lahir dengan Presentasi Bokong

\section{Daftar Pustaka}

1. Kayem G, Goffinet F, Clement D, Hessabi M, Carbol D. Breech presentation at term: morbidity and mortality according to the type of delivery at Port Royal Maternity Hospital from 1993 through 1999. Eur J Obstet Gynecol Reprod Biol 2002;102:137-42.

2. Cheng M, Hannah ME. Breech delivery at term: a critical review of literature. Obstet Gynecol 1993;82:605-18.

3. Hannah ME, Hannah WJ, Hewson SA. Planned caesarean section versus planned vaginal birth for breech presentation at term: a randomized multicentre trial. Lancet 2000;365:1375-83.

4. Fischer R, Witlin A, Tavalera, Legro RS. Breech presentation. Diunduh dari: www.emedicine.com. Diakses pada tanggal 11 Juli 2006.

5. Belfrage P, Gjessing L. The term breech presentation. A retrospective study with regard to the planned mode of delivery. Acta Obstet Gynecol Scand 2002;81:544-50.

6. Herbsti A, Thorngren-Jerneck K. Mode of delivery in breech presentation at term: increased neonatal morbidity with vaginal delivery. Acta Obstet Gynecol Scand 2001;80:731-37.
7. Uotila J, Yumala R, Kirkinen P. Good perinatal outcome in selective vaginal breech delivery at term. Acta Obstet Gynecol Scand 2005;84:578-83.

8. Guiliani A, Scholl WMJ, Basver A, Tamussino KF. Mode of delivery and outcome of 699 term singleton breech delivery at a single center. Am J Obstet Gynecol 2002; 187:1694-8.

9. Heija AA, Ali AM. Is breech presentation in nulliparous women at term an absolute indication for cesarean section? Ann Saudi Med 2001;21:190-3.

10. Bakry F, Moninca HE, Budjang RF, Aminullah A, Rulina S. Perinatal mortality and morbidity in breech deliveries at the Dr. Ciptomangunkusumo General Hospital, Jakarta. Pediatr Indones 1976;16:225-37.

11. Harahap FP. Trauma lahir pada bayi lahir sungsang. Tesis, 1986.

12. Kolatat T, Vanprapar N, Thitadilok W. Perinatal asphyxia: multivariate analysis of risk factor. J Med Assoc Thai 2000;83:1039-44.

13. Lieberman JR, Fraser D, Mazor M, Chaim W, Karplus M, Katz M. Breech presentation and cesarean section in term nulliparous women. Eur J Obstet Gynecol Reprod Biol 1995;61:111-5. 